\title{
A proposal for a methodological approach to the characterisation of Widespread Landslide Events: an application to Southern Italy
}

\author{
G. Gullà ${ }^{1}$, T. Caloiero ${ }^{2}$, R. Coscarelli ${ }^{1}$, and O. Petrucci ${ }^{1}$ \\ ${ }^{1}$ National Research Council - Research Institute for Geo-Hydrological Protection (CNR-IRPI), Cosenza, Italy \\ ${ }^{2}$ National Research Council - Institute for Agricultural and Forest Systems in the Mediterranean (CNR-ISAFOM), \\ Cosenza, Italy
}

Correspondence to: O. Petrucci (petrucci@irpi.cnr.it)

Received: 29 October 2010 - Revised: 23 November 2011 - Accepted: 3 January 2012 - Published: 17 January 2012

\begin{abstract}
This paper presents a methodological approach to both identifying and characterising Widespread Landslide Events (WLE), defined as the occurrence of several landslides through wide areas (thousands of square kilometres). This approach is based on a comparative analysis of two historical databases: a rainfall database and a landslide database, both concerning the same period.

This methodology was tested on Calabria (Southern Italy) by analysing a period of more than $80 \mathrm{yr}$. The data allowed the individuation of 25 WLEs generated by the following: (a) a single rainfall event (RE), (b) a few distinct but temporarily close REs, or (c) several consecutive REs occurring over a period of up to two months. An empirical curve, obtained by interpolating the number of landslides occurred during the WLEs and the average values of cumulative rainfall that triggered them enables the individuation of the relationship between rainfall and number of landslides.

The proposed methodological approach can be used wherever historical series of both rainfall and landslides are available. The results can be useful for monitoring the development of events and for the planning of emergency management.
\end{abstract}

\section{Introduction}

Each year, landslides triggered by rainfall are responsible for considerably greater economic losses and casualties than is generally recognised, and these losses are expected to increase worldwide due to the pressure of population expansion towards unstable hillside areas (Schuster and Highland, 2007; Barredo, 2009). A rough estimate of the effects related to major landslide events that occur on a global scale can be found in the figures reported by the available international databases (EM-DAT, 2010; Munich Re, 2010). However, these figures can be underestimated, and they usually differ from each other because of the scale upon which these data are collected and the severity threshold required for a landslide to be entered into a database (Kirschbaum et al., 2009). The international literature widely recognises that rainfall is the most common trigger of landslides (Crozier, 1986; Corominas, 2000), even though the relationship between rain and slope instability is not direct. Differences in geologic, geomorphologic, climatic and geotechnical factors make it difficult to identify a universal amount of rain that is able to trigger landslides everywhere. The rainfall "threshold" for triggering landslides can vary from one area to another, and it can change as a function of the mean annual precipitation, whereas the magnitude of the event depends on rainfall intensity (Campbell, 1975; Caine, 1980; Crozier, 1986; Keefer et al., 1987; Wieczoreck, 1987; Clarizia et al., 1996; Sandersen et al., 1996; Au, 1998; Polemio and Petrucci, 2010). Nevertheless, for different landslide categories (shallow, medium deep, deep) and in geologically homogeneous contexts, triggering scenarios can, in fact, be defined (Gullà et al., 2008; Terranova et al., 2007). Difficulties increase when the problem is extended both in space and time by analysing a sequence of landslides triggered through prolonged periods on a wide region instead of a restricted study area (or a single landslide) in a limited period (or during a single activation phase). In fact, historical landslide series show that sequences of slope instabilities can affect wide areas during almost the entire rainy season (Petrucci and Pasqua, 2008). The literature tends to divide these complex problems into single (and relatively less difficult) problems essentially by restricting either the observation period or the size of the study area. 
Nevertheless, an analysis of the phenomena as they actually occur - through a sequence lasting from a few to several days and scattered over a wide region - can supply indications for the management of emergency which occurs during the severest cases. In fact, during rainy seasons, the number of triggered landslides increases with time, and these phenomena often affect road networks, create traffic blockages, and delay the work of the agencies involved in managing emergency and civil protection actions. For these reasons, if, during rainy periods, these agencies can access information on the regional sectors that are going to be involved in widespread landslides events similar to those already occurred in the past, they could organise specific management plans that take into account the expected characteristics of the event.

In this study, we propose a methodology to both individuate and characterise Widespread Landslide Events (WLEs), defined as the occurrence of several landslides triggered by rainfall through wide areas (thousands of square kilometres) and throughout periods ranging from a few days to a few months. According to previous authors, the extent of the involved area is an indicator of the magnitude of landslide events. For example, Smolka (2006) defines "extreme natural events" as events that have serious regional or even global consequences. After the description of the proposed methodological approach, an application to an Italian region is discussed, highlighting both the limitations and possible applications of the results.

\section{Methodology}

The proposed approach is based on a comparative analysis of two series of historical data concerning rainfall and landslides triggered by rainfall. This comparison aims to individuate rainfall events that may trigger WLEs. In the following sub-sections, the characteristics of the data used and the main steps of their elaboration are described (Fig. 1).

\subsection{The rainfall database}

Rainfall data registered by the instruments of a measurement network have to be collected (R1 in Fig. 1). Each rain gauge in the network must be identified by a code and characterised using information about its location, type of registration instrument, and acquisition period. These data are usually collected by national or regional administrations. Depending on the instrument type these data can be sub-hourly, hourly or daily. For the aim of this study, daily rainfall data were needed; for each rain gauge, the dataset comprised the list of daily measured rainfall starting from the first year of the registration period.

Before conducting any rainfall analysis, it is important to analyse both the spatial distribution of the rain gauges and the data quality. In fact, to investigate the relationship between landslides and rainfall events, rain gauges must be distributed throughout the study area, and the rainfall series must not present inhomogeneities due to factors such as rain gauge relocations, changes in observation procedures, methods of calculating mean values, or the sources of data (Karl and Williams, 1987; Peterson and Easterling, 1994; Jones, 1995; Young, 1993; Jones et al., 1987).

Inhomogeneity is one of the most problematic factors affecting the quality of a long dataset such as daily rainfall series. Among the methods currently used to solve homogeneity problems (R2 in Fig. 1), none is unique and objective, and the choice of the most suitable procedure is strictly related to both the dataset characteristics (e.g. metadata availability and rain gauges density) and the examined area (Peterson et al., 1998; Aguilar et al., 2003). Some methods have been proposed in the scientific literature to deal with the homogenisation of daily series (Brunetti et al., 2004; Della-Marta and Wanner, 2006; Mestre et al., 2011). For example, the procedure discussed in Brunetti et al. (2012), which is based on the Craddock test (Craddock, 1979), may be suggested. After the homogenisation procedure (R3 in Fig. 1), for each rain gauge, the series of the historical rainfall events can be obtained, thus defining a Rainfall Event (RE) as a group of rainy days preceded and followed by at least one day with no rain. Thus, a rainfall events database is created from the rainfall database (R4 in Fig. 1). For each RE, the following data can then be collected: the duration (days), the cumulated rainfall $(\mathrm{mm})$, the maximum daily rainfall $(\mathrm{mm})$, and the average intensity, expressed as the ratio between the cumulated rainfall and the duration of the event $\left(\mathrm{mm} \mathrm{day}^{-1}\right)$.

\subsection{The landslide database}

Historical data on the damage caused by landslides triggered by rainfall, which we define in the following LRs (Landslide Records), can be mined by different types of documents and texts. Historical data are affected by several types of complications (Glade, 2001; Glaser and Stangl, 2004; Llasat et al., 2006; Devoli et al., 2007; Petrucci and Pasqua, 2008; Petrucci and Gullà, 2010). Nevertheless, especially in countries where there is no unique public authority collecting data, a specific historical research may be the only way to obtain the series of landslides which affected a study area. If more than one information source is available, crosscheck data validation, data gap filling and the checking of data reliability can be performed. The level of detail of landslide description depends on the type of historical document and the skill of the documents' author. Some of the available data, such as newspapers, focus more on the effects (damage) and less on their cause (the landslide). In addition, the availability of data changes over time and is related to event severity. Information concerning older events is generally less plentiful than information pertaining to newer events, and often the greatest amount of data exists for the most severe events, whereas less severe cases are rarely mentioned. It is 


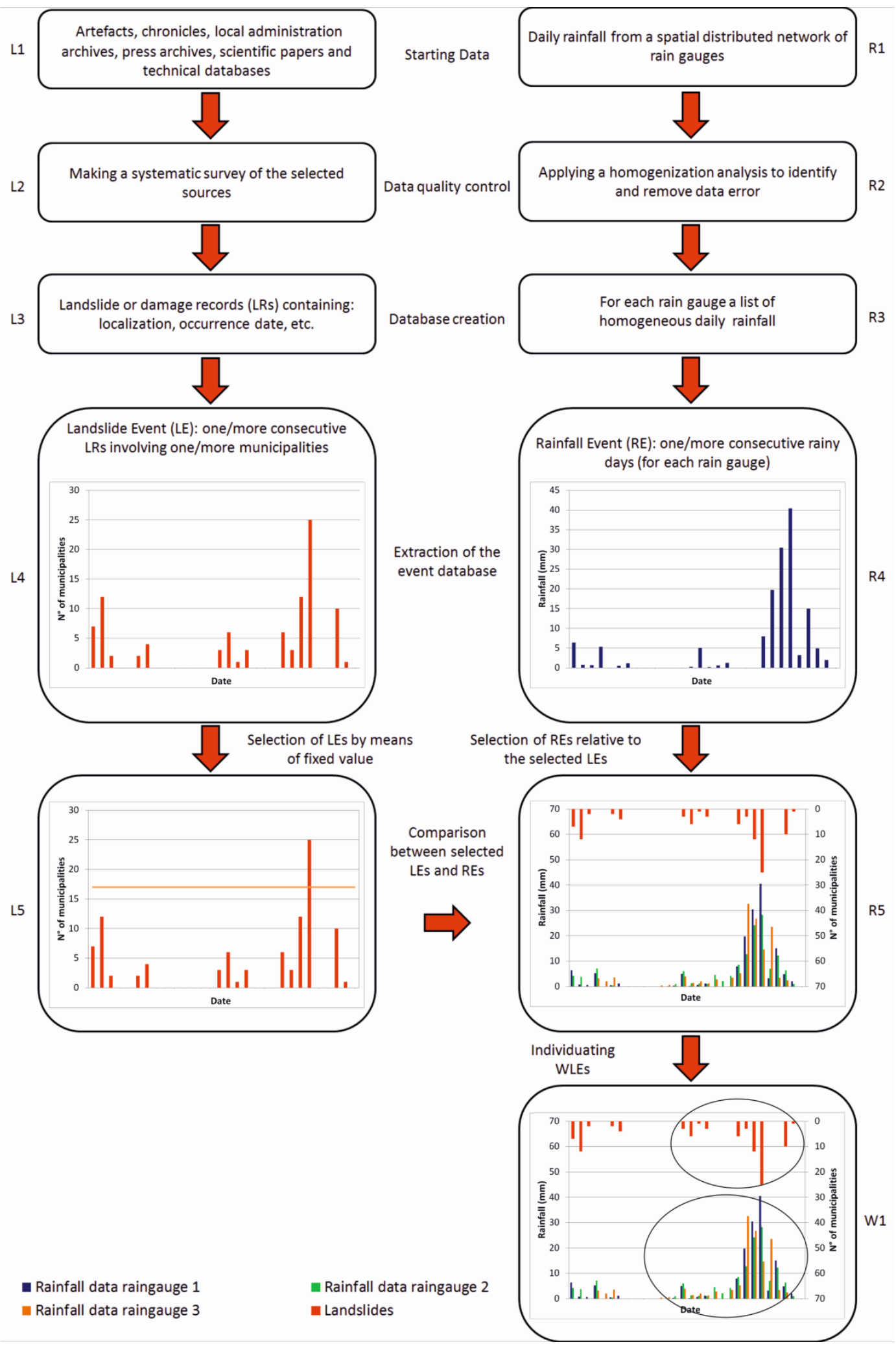

Fig. 1. Flow-chart showing the proposed methodology. 

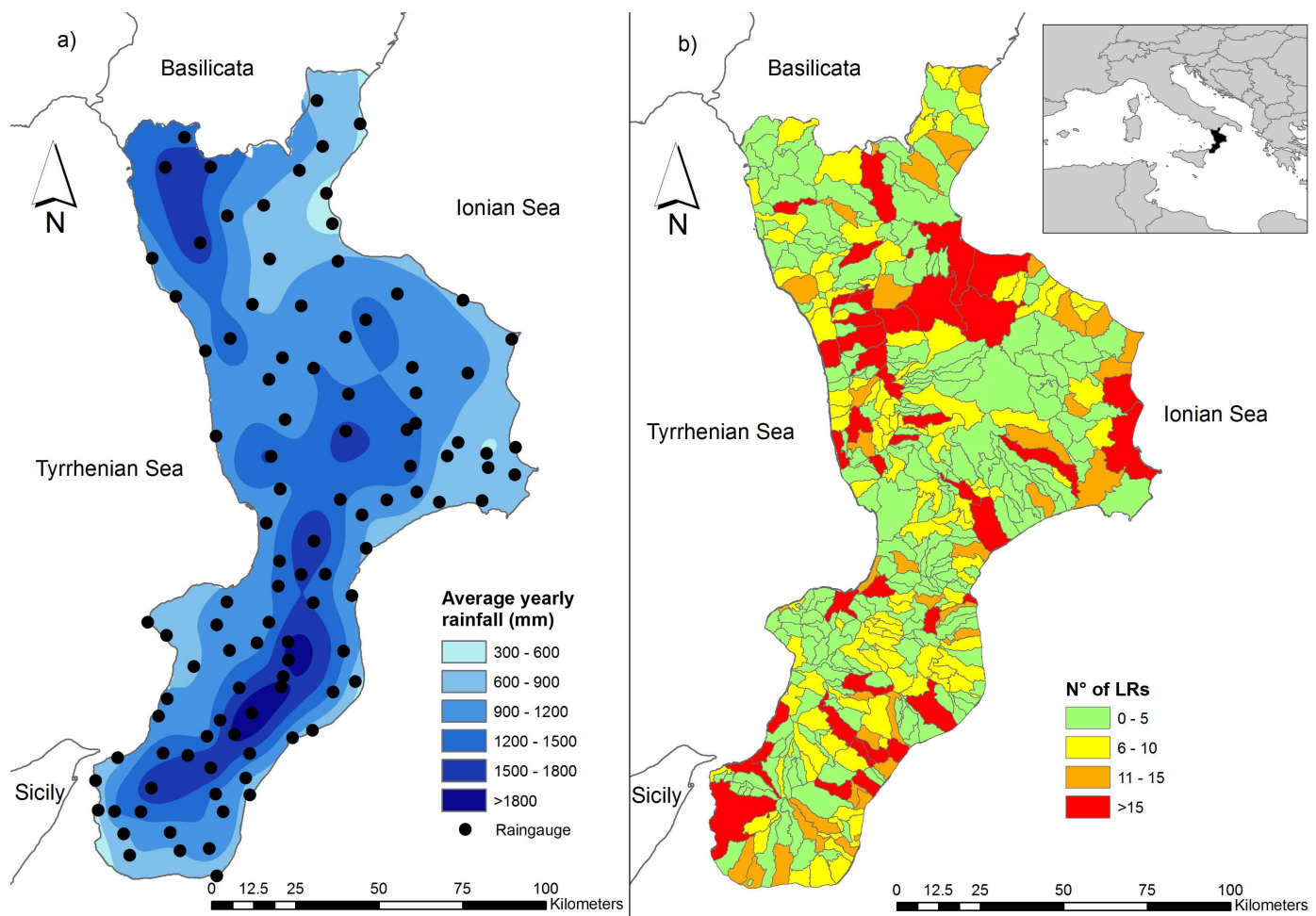

Fig. 2. The map of the study area indicating: (a) the rain gauges used in the application and the distribution of the average yearly rainfall; (b) the municipalities of Calabria coloured according to the number of landslide reports registered.

important to stress that the great majority of landslides included in the database caused some type of damage, so landslides occurred in unpopulated areas (which did not induce damage) may not be recorded.

Usually, the data quote the place names where the landslides occurred, but unless the document is a scientific article, the author does not supply maps of the hit areas, which means the area actually affected cannot be delimited. Even the type of landslide and its depth can only be obtained from scientific articles. Generally, however, these articles represent a low percentage of the available historical sources (less than $10 \%)$, and they often concern the most recent cases. Still, indirect information on landslide depth can be inferred from some types of sources (e.g. reports written by technicians of public works agencies), but this is not a rule, so this parameter cannot be extensively taken into account. Considering these limitations, a historical research project can be planned (L1 in Fig. 1). First, an inventory of data sources available through the study period (e.g. artefacts, chronicles, diaries, local administration archives, private and ecclesiastical archives, archives of local and regional agencies, press archives, scientific papers and technical databases) has to be drawn. As it is impossible to investigate all archives, priority analyses are necessary. Second, a systematic survey of the selected sources must be planned and performed to mine the documents describing landslides (L2 in Fig. 1). The acquisition of documents requires a certain amount of time according to their format. For example, photocopies, scanned files or digital photos of documents require typing, while digital archives allow a rapid copy and paste procedure. And third, paper documents should be converted into digital text files, and each piece of information concerning a landslide is stored as a database record, identified by the date of landslide occurrence and the municipality in which it occurred (L3 in Fig. 1). Then the records should be chronologically sorted in a landslide database.

\subsection{Widespread Landslide Events identification}

In the landslide database, a Landslide Event (LE) is the occurrence of one or more LRs during one or more consecutive days preceded and followed by at least one day without an LR. For each LE, the following data must be collected (L4 in Fig. 1): the starting date, the duration (number of days), the number of LRs, the number of municipalities hit, and the ratio between the sum of the areas of the municipalities hit and the whole regional area, called by Petrucci et al. (2008) the Index of the Damaged Area (IDA).

Fixing an arbitrary value for either the number of the municipalities hit or the IDA, the sub-set of LEs can be selected (L5 in Fig. 1). For each of the above-selected LEs, the analysis of rainfall allows us to define the whole period in which one or more REs presumably have caused one or more LEs (R5 in Fig. 1). Now, by reanalysing the LE data through the whole period covered by the RE, further LEs can be detected 


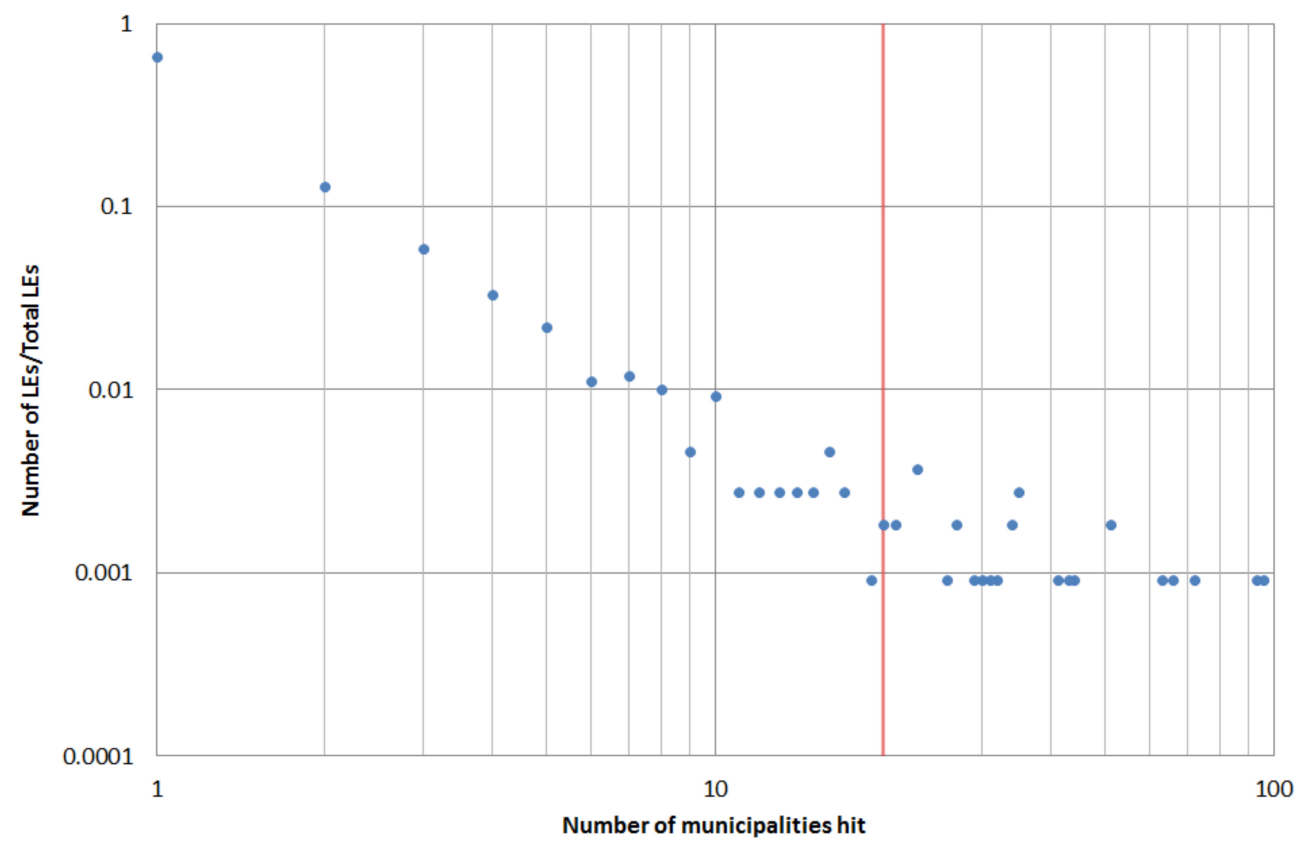

Fig. 3. Number of municipalities hit (x-axis) and ratio between the corresponding Landslides Events (LEs) and the total LEs registered in the whole Calabria (y-axis). The red line corresponds to 20 municipalities.

(even if affecting a smaller number of municipalities). The whole of the LEs that occurred through the period covered by the RE (W1 in Fig. 1) can be defined as Widespread Landslide Event (WLE). Then a WLE is composed by one or more LEs, at least one of which involved a number of municipalities (or a percentage of regional area) greater than a fixed value. The size of the involved area (greater than some thousands of square kilometres) can be used as a sort of proxy indicator of the event's impact because an increase of hit area generally produces higher costs for damage restoration and an increasing need for coordination efforts in emergency management procedures.

If the total number of landslide reports available for each WLE is put in relation to the Average Cumulated Rainfall (ACR) (that is the ratio between the sum of all the cumulated rainfall of the REs, registered at the rain gauges of the areas where landslides occurred, and the number of rain gauges), one or more curves can be drawn. These curves can be used in a predictive way because they roughly correlate a certain average of cumulative rainfall to a certain number of landslide reports.

Then, if both rainfall and landslide reports are monitored, it can be understood if and where a WLE is going to take place. In fact, by constantly upgrading cumulative rainfall, it is possible to detect in advance if the average cumulative rainfall is reaching a value that can generate a WLE. The monitoring of these data may supply information that can improve both the coordination of emergency phases and the support of the post-event management.

\section{Application to the Calabrian territory}

An application of the proposed methodology was conducted for Calabria, a region of Southern Italy that has an area of $15080 \mathrm{~km}^{2}$ and a perimeter of approximately $738 \mathrm{~km}$. Calabria is characterised by elevations up to $2000 \mathrm{~m}$ a.s.l. and high climatic contrasts. The climate of the region is classified as Mediterranean: during the summer, precipitation is less frequent (except for some occasional thunderstorms), while during the winter, rainfall is frequent throughout the region, and snow occurs at the highest elevations (Caloiero et al., 2011). The Ionian side of the region is particularly influenced by the warm currents coming from Africa, which cause high temperatures with short and heavy precipitation. In contrast, the Tyrrhenian side receives western air currents and has milder temperatures and frequent orographic precipitation. In the inland zones, colder winters - with snow - and cooler summers are typical (Versace et al., 1989; Caloiero et al., 1990).

From a geological point of view, Calabria is made up of allochthonous crystalline rocks (from the Palaeozoic to the Jurassic), stacked during the middle Miocene (Tortorici, 1982) over carbonate units (Ogniben, 1973). Neogene flysch fills tectonic depressions. Starting from the Quaternary, the region has been subjected to still-active uplift. Tectonic stresses and climatic conditions deteriorate the characteristics of rocks, predisposing slopes to instability (Borrelli et al., 2007). Landslides are common in Calabria, especially during rainy season. Either prolonged rainy periods, characterised by low daily intensities, or short and intense storms 
Table 1. The main characteristics of the REs and the LEs, identifying the 25 WLEs.

\begin{tabular}{|c|c|c|c|c|c|c|c|}
\hline WLE & $\mathrm{RE}$ & LE & $\begin{array}{r}\text { No. of } \\
\text { Rain } \\
\text { Gauges }\end{array}$ & $\begin{array}{r}\text { Max } \\
\text { Intensity } \\
\left(\mathrm{mm} \mathrm{day}^{-1}\right)\end{array}$ & $\begin{array}{r}\text { Max } \\
\text { Cumulative } \\
\text { Rainfall }(\mathrm{mm})\end{array}$ & $\begin{array}{r}\text { Max event } \\
\text { Duration } \\
\text { (days) }\end{array}$ & $\begin{array}{r}\text { Municipalities } \\
\text { hit area } \\
\left(\mathrm{km}^{2}\right)\end{array}$ \\
\hline 1 & 13-24 Nov 1935 & 21-24 Nov 1935 & 20 & 509.1 & 758.8 & 12 & 923.8 \\
\hline 2 & 9-27 Jan 1940 & 10-29 Jan 1940 & 28 & 201.9 & 560.7 & 17 & 2168.2 \\
\hline 3 & 24 Nov-8 Dec 1944 & 27 Nov-4 Dec 1944 & 26 & 172.5 & 286.5 & 13 & 2392.8 \\
\hline 4 & 5-29 Oct 1951 & 5-29 Oct 1951 & 44 & 534.6 & 1760.3 & 22 & 1973.0 \\
\hline 5 & 18 Oct-11 Nov 1953 & 18 Oct-15 Nov 1953 & 50 & 292.6 & 1004.7 & 22 & 2387.4 \\
\hline 6 & 31 Jan-29 Feb 1954 & 31 Jan-26 Feb 1954 & 52 & 134.1 & 599.8 & 24 & 2333.5 \\
\hline 7 & 30 Jan-2 Mar 1956 & 2 Feb-2 Mar 1956 & 23 & 77.2 & 475.2 & 30 & 1685.0 \\
\hline 8 & 6 Oct-27 Nov 1957 & 6 Oct-29 Nov 1957 & 46 & 200.2 & 1167.2 & 39 & 4593.3 \\
\hline 9 & 20-27 Nov 1959 & 21-26 Nov 1959 & 32 & 246.7 & 435.8 & 8 & 1847.8 \\
\hline 10 & 28 Sep-6 Oct 1971 & $1-4$ Oct 1971 & 25 & 274.1 & 575.4 & 9 & 1331.0 \\
\hline 11 & 12 Dec 1972-4 Feb 1973 & 14 Dec 1972-4 Feb 1973 & 62 & 433.4 & 1697.4 & 44 & 5180.9 \\
\hline 12 & 26 Oct-23 Dec 1976 & 26 Oct-27 Dec 1976 & 51 & 309.0 & 1822.6 & 59 & 3282.8 \\
\hline 13 & 3 Jan-27 Feb 1981 & 3 Jan-23 Feb 1981 & 15 & 173.4 & 663.5 & 35 & 1847.3 \\
\hline 14 & 20 Dec 1984-21 Jan 1985 & 2-21 Jan 1985 & 37 & 197.4 & 960.7 & 33 & 2510.9 \\
\hline 15 & 15-18 Nov 1987 & 15-16 Nov 1987 & 21 & 290.4 & 291.0 & 4 & 1161.1 \\
\hline 16 & 24 Feb-14 Mar 1988 & 2 Mar-15 Mar 1988 & 36 & 308.1 & 488.7 & 13 & 2001.6 \\
\hline 17 & 5-29 Dec 1990 & 15-28 Dec 1990 & 23 & 231.2 & 477.0 & 24 & 1934.0 \\
\hline 18 & 22 Jan-9 Feb 1996 & 23 Jan-8 Feb 1996 & 30 & 252.0 & 727.8 & 18 & 2401.9 \\
\hline 19 & 3-15 Oct 1996 & 3-14 Oct 1996 & 40 & 236.2 & 477.8 & 13 & 2694.4 \\
\hline 20 & $10-26 \operatorname{Jan} 2000$ & 14-20 Jan 2000 & 25 & 220.4 & 473.6 & 16 & 1216.4 \\
\hline 21 & 7-11 Sep 2000 & 7-13 Sep 2000 & 32 & 301.6 & 562.2 & 5 & 2779.5 \\
\hline 22 & 21 Nov 2002-1 Feb 2003 & 22 Nov 2002-8 Feb 2003 & 75 & 140.2 & 955.4 & 69 & 4455.6 \\
\hline 23 & 3-16 Nov 2004 & 3-16 Nov 2004 & 40 & 206.4 & 420.4 & 14 & 1610.5 \\
\hline 24 & 20 Nov 2008- 9 Feb 2009 & 20 Nov 2008-25 Feb 2009 & 105 & 256.4 & 1616.8 & 86 & 7657.5 \\
\hline 25 & 19 Sep-4 Oct 2009 & 24 Sep-3 Oct 2009 & 41 & 336.8 & 831.6 & 14 & 2505.7 \\
\hline
\end{tabular}

can trigger landslides, often resulting in damage and casualties (Petrucci et al., 2010).

The rainfall data used in this study were extracted from the hydrological database of the former Servizio Idrologico Italiano, now Centro Funzionale Multirischi della Calabria (http://www.cfcalabria.it). A preliminarily analysis of the data, through the available metadata, was performed to remove inhomogeneities. The procedure proposed by Brunetti et al. (2012) was applied. Each rainfall series was tested against other series by means of a multiple application of the Craddock test (Craddock, 1979) in sub-groups of 10 series. Once one break in the signal was identified, the series used to estimate the adjustments were chosen among the neighbouring series, which resulted homogeneous in a sufficiently long sub-period centred on the break year, and they were well correlated with the candidate one. The final set of daily adjustments was then calculated by averaging all the yearly cycles, excluding from the computation those rain gauges whose set of adjustments showed an incoherent behaviour compared with the others. Fifteen rainfall series starting from 2001 can be assumed as homogeneous because the rain gauge network in Calabria did not have significant changes since 2001. Ninety series, which began operating even before 2001, were classified as homogeneous or as being homogenised using the procedure described in the previous paragraph. Finally, a set of 105 homogeneous daily rainfall series recorded in the period 1921-2009 was created. Figure 2a shows the spatial distribution of the average yearly precipitation and the locations of the 105 rain gauges. More than 200000 REs were extracted from the homogeneous daily rainfall series registered in these rain gauges. These REs had a maximum duration of 50 days, an average of 2.4 days, a maximum intensity of approximately $535 \mathrm{~mm} \mathrm{~d}^{-1}$, and a maximum cumulative rainfall of $1823 \mathrm{~mm}$.

A wide historical archive containing data on damaging floods and landslides that occurred through the past centuries in Calabria has been implemented since 2000 by means of a systematic analysis of historical sources. From this database, 3451 records of landslides occurring in the 409 municipalities of Calabria from 1921-2009 were selected and chronologically sorted. The maximum number of records per municipality is 85 , while the average number of records per municipality is 8.4. Figure $2 \mathrm{~b}$ shows the distribution of landslides per municipality. A total of 1085 LEs were identified, with a maximum duration of 15 days and an average duration of 1.4 days. On average, there were 2.7 LEs per municipality, and the maximum number of LEs per municipality was 81 ; only 9 municipalities had no LEs. The maximum number of LRs per LE was equal to 133 , while the average number was 3.2 . 
The data show that approximately $66 \%$ of the LEs involved only one municipality, and approximately $13 \%$ involved two municipalities. Similar indications are also obtained when referring to the surface of the municipalities involved in the identified LEs. Figure 3 represents, in a log-log scale, the number of municipalities hit, on the x-axis, and the ratio (on the y-axis) between the corresponding Landslides Events (LEs) and the total LEs registered in the study area (the whole Calabria). The curve of experimental points shows a slope change when approaching the 20 municipalities. Thus, for Calabria, it was considered reasonable to assume a value of 20 municipalities to select LEs that can produce WLEs. The WLEs have been defined on the basis of the distribution of REs in a time window identified as specified in the methodology paragraph and shown in Fig. 4, in which three different examples of WLEs are presented: (a) a WLE generated by a single RE (Fig. 4a); (b) a WLE generated by few distinct but temporarily close REs (Fig. 4b); (c) a WLE generated by several consecutive REs occurring over a long period (Fig. 4c).

The data enabled the individuation of 25 WLEs: 8 were generated by a single RE, 10 by several distinct but temporarily close REs, and 7 by various REs occurring over a long period (1-2 months). Table 1 shows the list and the main characteristics of both the 25 WLEs and the relative REs that caused them. The 25 WLEs occurred between September and March, and they affected a number of municipalities between 22 and 177, whereas the number of LRs was between 23 and 314 . The number of rain gauges representative of the areas hit by the landslides ranged between 15 and 105 (average of approximately 39). The REs that caused the 25 WLEs had variable durations: from a few days to long periods covered by several consecutive REs ( 86 days for WLE no. 24 in Table 1). The REs had cumulative rainfall ranging between 286 and $1822 \mathrm{~mm}$ and intensities (equal to the ratio between the cumulative rainfall and the rainy days of each RE) ranging between 77 and $534.6 \mathrm{~mm} \mathrm{day}^{-1}$. By reporting on semi-log scale, the number of LRs during the identified WLEs versus the ACR of the REs recorded in the rain gauges of the area affected by LRs, an empirical curve (Guide Curve - GC) interpolating the experimental points can be drawn (Fig. 5) and a formulation has also been determined.

Each point of this curve characterises, through the number of LRs, the WLE that could occur in Calabria for a defined value of ACR. Two enveloping curves (lower bound and upper bound) on the two opposite sides of the GC were drawn to individuate a buffer area enclosing all the experimental points. Moreover, the two enveloping curves provide, for a given value of ACR, the minimum and maximum LR values that could occur during the WLE generated by the given ACR.

The abrupt variation of the gradient shown by the GC in proximity of an ACR value of approximately $700 \mathrm{~mm}$ indicates the passage to WLEs characterised by high LR values.

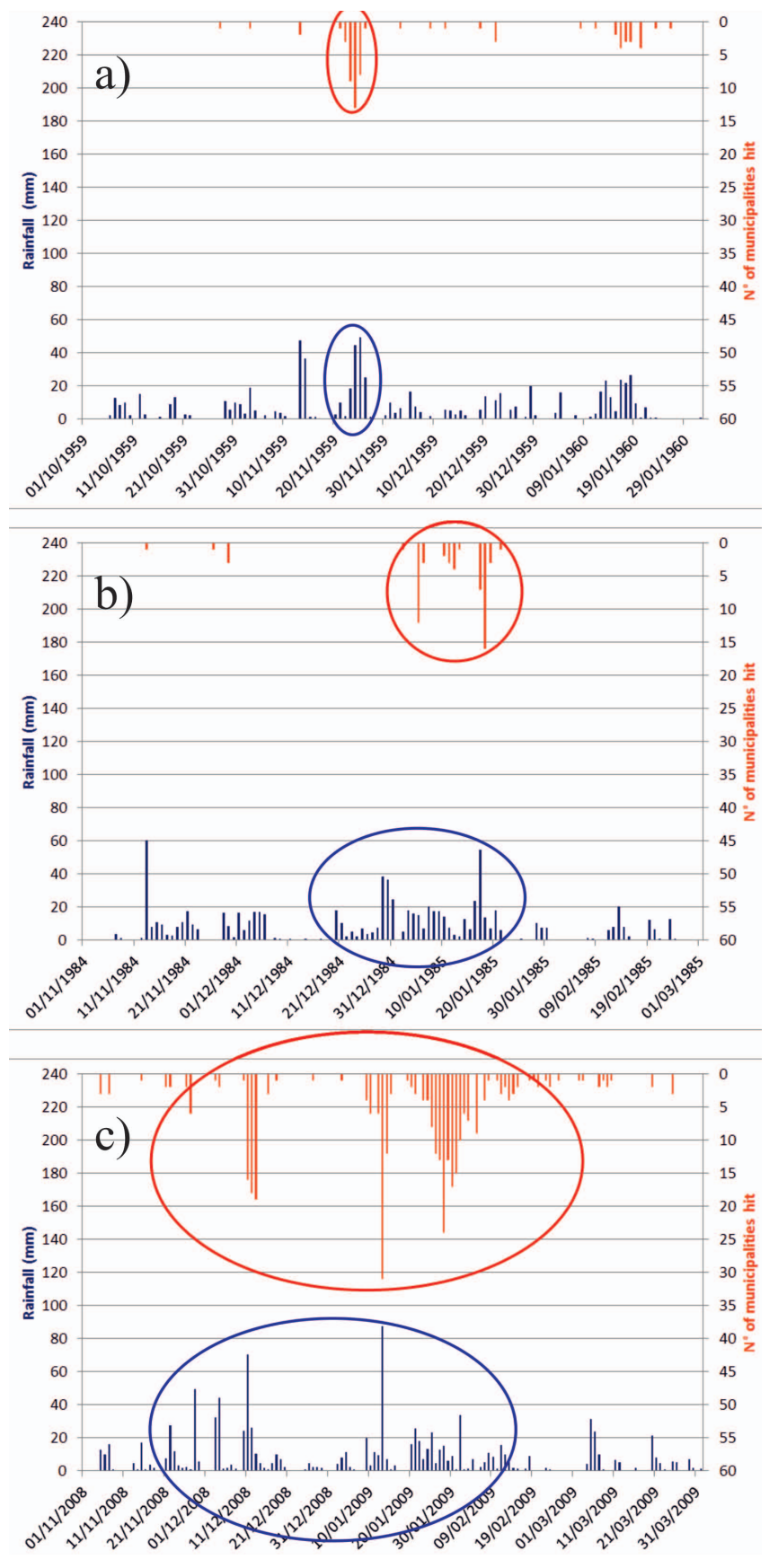

Fig. 4. Three different cases of WLE: (a) a WLE generated by a single RE; (b) a WLE generated by a few distinct but temporarily close REs; and (c) a WLE generated by several consecutive REs occurred throughout a long period.

\section{Conclusions}

A methodological approach to both identify and characterise Widespread Landslide Events, defined as the occurrence of several landslides through wide areas (thousands of square kilometres), is proposed. The approach is based on the 


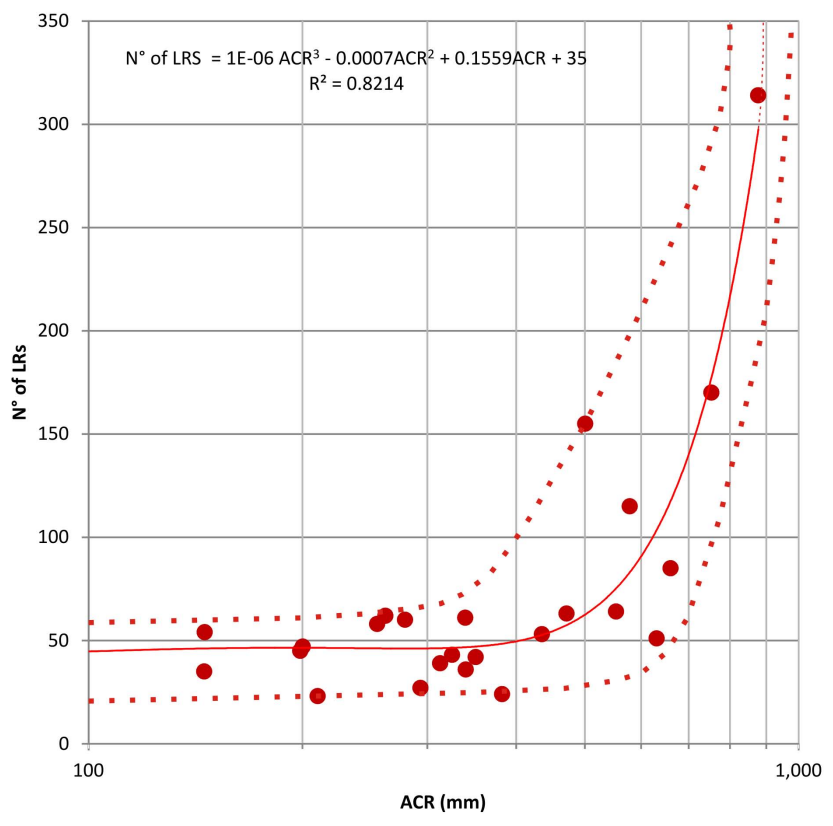

Fig. 5. Number of LRs, during the identified 25 WLEs, versus the ACR of the REs recorded in the rain gauges of the area affected by LRs. The solid line is the empirical curve (Guide Curve) interpolating the experimental points (with its mathematical formulation) and the dashed lines are the enveloping curves enclosing all the experimental points.

comparative analysis of two databases relative to the rainfall events and landslide events.

During a WLE, one or more LEs, at least one of which involves a number of municipalities greater than a fixed value, develop on a period that can reach even duration of two months.

An application of the methodology to the Calabria region allowed the individuation of more than 1000 LEs, and approximately 200000 REs occurred in the period 1921-2009. By filtering the LEs affecting a fixed number (20) of municipalities, 25 WLEs were individuated. Thus, an empirical curve (Guide Curve) interpolating the average cumulative rainfall (ACR) and the number of landslide reports (LRs) was obtained. This curve allows an approximate individuation of the number of LRs which, during a WLE, can be expected after a certain value of ACR.

Thus, during a rainy period, a comparative analysis of the collected landslide report data and a monitoring of the average cumulated rainfall could enable the identification of a WLE onset and, accordingly, the selection of the most suitable emergency strategy calibrated on similar cases that occurred in the same region.

The proposed methodology can be used anywhere historical series of rainfall and landslides are available, even if the results obtained may vary from region to region. The weakest aspect of the methodology is that it requires detailed and laborious work to identify both the historical REs and the LEs.
The procedure is not automatic, but once calibrated over a wide study area, it can provide useful results that can be applied for the purpose of emergency management planning. The number of LRs, through the defined GC, could provide a preliminary assessment of the impact of the corresponding WLE. The methodology can be oriented towards WLE impact assessment using a more detailed scale and evaluating damage data.

Acknowledgements. This study has been carried out within the Subproject "Tipizzazione di eventi naturali ed antropici ad elevato impatto sociale ed economico", as part of the Project "Rischi naturali, ambientali e antropici" - Department "Terra e Ambiente' of the Italian National Research Council (CNR).

The authors are grateful to the Editor and the anonymous reviewers for the precious remarks and comments which led to improve the initial version of this paper.

Edited by: M.-C. Llasat

Reviewed by: three anonymous referees

\section{References}

Aguilar, E., Auer, I., Brunet, M., Peterson, T. C., and Wieringa, J.: Guidelines on Climate Metadata and Homogenization, World Climate Programme Data and Monitoring WCDMP-No.53, WMO-TD No. 1186, WMO, Geneva, 2003.

$\mathrm{Au}, \mathrm{S}$. W. C.: Rain induced slope instability in Hong Kong, Eng. Geol., 51, 1-36, 1998.

Barredo, J. I.: Normalised flood losses in Europe: 19702006, Nat. Hazards Earth Syst. Sci., 9, 97-104, doi:10.5194/nhess-9-972009, 2009.

Borrelli, L., Greco, R., and Gullà, G.: Weathering grade of rock masses as a predisposing factor to slope instabilities: Reconnaissance and control procedures, Geomorphology, 87, 158-175, 2007.

Brunetti, M., Maugeri, M., Monti, F., and Nanni, T.: Changes in daily precipitation frequency and distribution in Italy over the last 120 years, J. Geophys. Res., 109, D05102, doi:10.1029/2003JD004296, 2004.

Brunetti, M., Caloiero, T., Coscarelli, R., Gullà, G., Nanni, T. and Simolo, C.: Precipitation variability and change in the Calabria region (Italy) from a high resolution daily dataset, Int. J. Climatol., 32, 55-73, doi:10.1002/joc.2233, 2012.

Caine, N.: The rainfall intensity-duration control of shallow landslides and debris flow, Geogr. Ann. A, 62, 23-27, 1980.

Campbell, R.: Soil slips, debris flows and rainstorms in the Santa Monica Mountains and vicinity, Southern California, USGS Professional Paper, 851, US Government Printing Office, Washington, DC, 1975.

Caloiero, D., Niccoli, R., and Reali, C.: Le precipitazioni in Calabria (1921-1980), Geodata n. 36, CNR-IRPI, Cosenza, 1990.

Caloiero, T., Coscarelli, R., Ferrari, E., and Mancini, M.: Trend detection of annual and seasonal rainfall in Calabria (Southern Italy), Int. J. Climatol., 31, 44-56, 2011.

Clarizia, M., Gullà, G., and Sorbino, G.: Sui meccanismi di innesco dei soil slip, International conference Prevention of hydrogeological hazards: the role of scientific research, 1, 585-597, 1996. 
Corominas, J.: Landslides and climate. Keynote lecture, in: Proceedings of the 8th International Symposium on Landslides, Balkema, Cardiff, 4, 1-33, 2000.

Craddock, J. M.: Methods of comparing annual rainfall records for climatic purposes, Weather, 34, 332-346, 1979.

Crozier, M. J.: Landslides: causes, consequences and environment, Croom Helm, London, 1986.

Della-Marta, P. M. and Wanner, H.: A method of homogenizing the extremes and mean of daily temperature measurements, J. Climate, G, 4179-4197, 2006.

Devoli, G., Morales, A., and Høeg, K.: Historical landslides in Nicaragua-collection and analysis of data, Landslides, 4, 5-18, 2007.

EM-DAT (The International Disaster Database): Centre for Research on the Epidemiology of Disasters (CRED), available at: http://www.emdat.be/, last access: June 2010.

Glade, T.: Landslide hazard assessment and historical landslide data - an inseparable couple?, in: The use of historical data in natural hazard assessments, Advances of Technological and Natural Hazard Research, edited by: Glade, T., Albini, P., and Frances, F., Kluwer, 153-169, 2001.

Glaser, R. and Stangl, H.: Climate and floods in central Europe since ad 1000: data, methods, results and consequences, Surv. Geophys., 25, 485-510, 2004.

Gullà, G., Antronico, L., Iaquinta, P., and Terranova, O.: Susceptibility and triggering scenarios at a regional scale for shallow landslides, Geomorphology, 99, 39-58, 2008.

Jones, P. D.: The instrumental data record: Its accuracy and use in attempts to identify the " $\mathrm{CO}_{2}$ " signal, in: Analysis of Climate Variability, edited by: von Storch, H. and Navarra, A., Springer Verlag, Berlin, 53-76, 1995.

Jones, P. D., Wigely, T. M. L., and Briffa, K. R.: Monthly mean pressure reconstructions for Europe (back to 1780) and North America (back to 1858), Tech. Note TR037, US Dept. of Energy, Washington, DC, 99 pp., 1987.

Karl, T. R. and Williams, C. N.: An approach to adjusting climatological time series for discontinuous inhomogeneity, J. Clim. Appl. Meteorol., 26, 1744-1763, 1987.

Keefer, D. K., Wilson, R. C., Mark, R., Brabb, E. E., Brown III, W. M., Ellen, S. D., Harp, E. L., Wieczorek, G. F., Alger, C. S., and Zatkin, R. S.: Real time landslide warning during heavy rainfall, Science, 238, 921-925, 1987.

Kirschbaum, D. B., Adler, R., Hong, Y., Hill, S., and Lerner-Lam, A.: A global landslide catalog for hazard applications: method, results, and limitations, Nat. Hazards, 52, 561-575, 2009.

Llasat, M. C., Barriendos, M., and Barrera, A.: The use of historical data in flood risk assessment. Application to Catalonia (NE Spain) 14th-20th centuries, View from the South, Environmental stories from the Mediterranean Word, in: CNR, edited by: Armiero, M., Istituto di Studi sulle Società del Mediterraneo, Napoli, Italy, 95-11, 2006.

Mestre, O., Gruber, C., Prieur, C., Caussinus, H., and Jourdain, S.: SPLIDHOM: A method for homogenization of daily temperature observations, J. Appl. Meteor. Climatol., 50, 2343-2358, doi:10.1175/2011JAMC2641.1, 2011.

Munich Re: Natural catastrophes 2010, Munich Re, 2010, available at: http://www.munichre.com/en/homepage/default.aspx, last access: June 2011.
Ogniben, L.: Schema geologico della Calabria in base ai dati odierni, Geologica Romana, 12, 243-585, 1973.

Peterson, T. C. and Easterling, D. R.: Creation of homogeneous composite climatological reference series, Int. J. Climatol., 14, 671-679, 1994.

Peterson, T. C., Easterling, D. R., Karl, T. R., Groisman, P., Nicholls, N., Plummer, N., Torok, S., Auer, I., Boehm, R., Gullett, D., Vincent, L., Heino, R., Toemenvirta, H., Mestre, O., Szentimrey, T., Salinger, J., Førland, E., Hanssen-Bauer, I., Alexandersson, H., Jones, P., and Parker, D.: Homogeneity adjustments of in situ atmospheric climate data: a review, Int. J. Climatol., 18, 1493-1517, 1998.

Petrucci, O. and Gullà, G.: A simplified method for landslide damage scenario assessment based on historical data, Nat. Hazards, 52, 539-560, 2010.

Petrucci, O. and Pasqua, A. A.: The study of past damaging hydrogeological events for damage susceptibility zonation, Nat. Hazards Earth Syst. Sci., 8, 881-892, doi:10.5194/nhess-8-8812008, 2008.

Petrucci, O., Polemio, M., and Pasqua, A. A.: Analysis of damaging hydro-geological events: the case of Calabria region (southern Italy), Environ. Manage., 25, 483-495, 2008.

Petrucci, O., Pasqua, A. A., and Gullà, G.: Landslide damage assessment using the Support Analysis Framework (SAF): the 2009 landsliding event in Calabria (Italy), Adv. Geosci., 26, 1317, doi:10.5194/adgeo-26-13-2010, 2010.

Polemio, M. and Petrucci, O.: Occurrence of landslide events and the role of climate in the twentieth century in Calabria, southern Italy, Q. J. Eng. Geol. Hydroge., 43, 403-415, 2010.

Sandersen, F., Bakkehøi, S., Hestnes, E., and Lied, K.: The influence of meteorological factors on the initiation of debris flows, rockfalls, rockslides and rockmass stability, Landslides, edited by: Senneset, K., Proc. of 7th Int. Symp. on Landslides, Trondheim, Rotterdam, Balkema, 1, 97-113, 1996.

Schuster, R. L. and Highland, L. M.: The Third Hans Cloos Lecture, Urban landslides: socioeconomic impacts and overview of mitigative strategies, Bull. Eng. Geol. Environ., 66, 1-27, 2007.

Smolka, A.: Natural disasters and the challenge of extreme events: risk management from an insurance perspective, Phil. Trans. R. Soc., 364, 2147-2165, 2006.

Terranova, O., Antronico, L., and Gullà, G.: Landslide triggering scenarios in homogeneous geological contexts: The area surrounding Acri (Calabria, Italy), Geomorphology, 87, 250-267, 2007.

Tortorici, L.: Lineamenti geologico-strutturali dell'Arco CalabroPeloritano, Rendiconti della Società Italiana di Mineralogia e Petrologia, 38, 972-940, 1982.

Versace, P., Ferrari, E., Gabriele, S., and Rossi, F.: Valutazione delle piene in Calabria, Geodata n.30, CNR-IRPI, Cosenza, 1989.

Wieczoreck, G. F.: Effect of rainfall intensity and duration on debris flows in central Santa Cruz Mountains, California, Geol. Soc. of America, Rev. Eng. Geol., 7, 93-104, 1987.

Young, K. C.: Detecting and removing inhomogeneities from longterm monthly sea level pressure time series, J. Climate, 6, 1205$1220,1993$. 